\title{
Laser-Induced Color Marking of Titanium: A Modeling Study of the Interference Effect and the Impact of Protective Coating
}

\author{
K. M. Lęcka, M. R. Wójcik, and A. J. Antończak \\ Faculty of Electronics, Wroclaw University of Science and Technology, Wyb. Wyspianskiego 27, 50-370 Wroclaw, Poland \\ Correspondence should be addressed to M. R. Wójcik; michal.wojcik@pwr.edu.pl
}

Received 20 March 2017; Revised 23 June 2017; Accepted 18 July 2017; Published 29 August 2017

Academic Editor: Michael Vynnycky

Copyright (c) 2017 K. M. Łęcka et al. This is an open access article distributed under the Creative Commons Attribution License, which permits unrestricted use, distribution, and reproduction in any medium, provided the original work is properly cited.

\begin{abstract}
Laser-induced color marking of metals, due to numerous advantages, including inter alia the high quality, resolution, durability, and noncontact methodology of surface marking, seems to be attractive for use in various applications. In this method, the resulting color is mainly evident from the interference effect. Therefore, one of the still unsolved problems on titanium is the color change after imposition of an additional layer (fingerprints, grease, etc.). In this paper, a computer simulation based on the theoretical thin layers model was presented. The results of the modeling study revealed that theoretically a thin protective coating of a known refractive index can be applied while still maintaining the target color. In this case, as a protective layer, an amphiphobic coating has been taken into consideration with its ability to resist surface contamination. The study was performed for titanium (grade 2). The model utilizes the real data derived from the spectrophotometer, as well as from the ellipsometry measurements of laser-induced samples.
\end{abstract}

\section{Introduction}

Laser-induced color marking of metals has been well known for 30 years [1] but to this day it has not been used widely in industry. High quality, difficulty to forge, wear resistance, and noncontact marking (no pressure, no deformation, and no pollution on the surface) are the main advantages of this method. The procedure utilizes a laser, which acts as a heat source allowing forming on a metal surface a thin transparent or semitransparent oxide film. If a beam of parallel monochromatic light falls, at an angle, onto a transparent or partly transparent layer, this beam is repeatedly reflected from the surfaces limited by the oxide layer (from the surface of both oxide and metal). By increasing the thickness of oxide on the surface and as a consequence by changing the interference effect (each wavelength has a different degree of attenuation or amplification), a color effect can be observed and controlled [2-5].

It is well known that titanium, because of its strong affinity with oxygen, when exposed to the atmosphere, becomes covered by a passive film with a thickness of a few nanometers. Numerous studies concerning various aspects of the laser-induced color marking of titanium as well as stainless steel have recently been published. In these papers, detailed characterizations of optical properties [3-9], changes in physicochemical properties $[3,5,6,8-11]$, oxide thicknesses $[3-6,8]$ and corrosion resistance [12-15] were conducted. It has also been found that a number of different process parameters such as laser power, scanning speed of the material, the size of the marked area, the temperature, and position of the sample exert a significant impact on the reproducibility of the resulting color [4]. In addition, the perception of the color depends on the angle of observation $[5,16,17]$. A single publication concerns the mathematical modeling of thin oxide layers on iron. However, the model focuses only on the problem of color prediction [18].

Numerous research has indicated a wide variety of applications for the color-marked parts, such as the automotive industry, electronics, decorative purposes, jewelry industry, aerospace, and medicine $[2,4,8,19-22]$. However, one of the still unsolved problems on laser-marked titanium substrates is the preservation of the color effect due to the external imposition of an additional layer in the form of, for example, water, grease, oily substances, fingerprints, or skin oil residue. Even though much work has recently been published concerning various aspects of color marking, only 
one has proposed a method for protecting thin oxide layers on anodized titanium [23]. In that paper, the authors showed that with the use of commercially available amorphous perfluoropolymer (fluoropolymer PFPE-S10, FLUOROLINK ${ }^{\circledR}$ S10) it is possible to protect one (purple) color. The experiments on other colors have not been mentioned. In order to increase the attractiveness and utility of laser color marking, there is a need to investigate the effect of imposing an additional, protective layer in order to preserve the color.

Fingerprint composition has been widely studied from a medical, dermatological, and forensic science point of view $[24,25]$. Since fingerprints are mainly composed of water and skin oil (sebum), antifingerprint properties were achieved by developing amphiphobic surfaces that repel water (hydrophobic) and oils (oleophobic) [23, 24, 26, 27]. Hydrophobic surfaces are quite commonly found in nature, especially in plants and insects, for example, plant leaves (lotus, rice, and lady's mantle leaf) [28-30], water strider legs [31], bird features [32], and butterfly wings [33, 34]. Moreover, biological surfaces (e.g., hierarchical, overhang, and reentrant structures) are characterized by low surface energy. The understanding of the mechanism of extraordinary waterproof and self-cleaning natural superhydrophobic surfaces has become the interest of many researchers. However, despite many advantages of transparent superhydrophobic coatings, they are not resistant to contamination in the form of an oil/grease layer (low surface tension) due to Mie light scattering, which leads to a decrease of optical transmittance in the visible range [35]. Due to the properties of oleophobic coatings, for example, an almost perfectly smooth surface (which makes the contact angle very big), refractive index between 1.43 and 1.47 [36], and a relatively low price, they seem to be perfect protective layers. Dust, grease, or other sources of contamination do not adhere to them. Furthermore, flexible oleophobic films are more scratch resistant than traditional glass. They are also very hydrophobic [37].

There exist, however, structures that contain both of the above-mentioned properties. Such structures are called amphiphobic. In order to create them not only topography (roughness), but also low surface energy, due to reducing intermolecular attractive forces and reducing adhesion of fingerprint materials on the surface, is required [24]. Nevertheless, due to the fact that the surface topography promotes light scattering, transparency decreases with the increase in roughness [38]. Good transparency requires surface roughness lower than $100 \mathrm{~nm}$ [39]. It is possible to fabricate a transparent, highly oleophobic, and superhydrophobic coating; however it is much more challenging $[40,41]$. Amphiphobic coatings are commonly used in many applications, including inter alia TV screens, tablets, solar panels, microfluidics, textiles, automobile, and eye lenses [41, 42].

Due to the above-mentioned facts, in this article, as the color protecting coating, amphiphobic (i.e., oleo- and hydrophobic) layers were chosen for simulation (a refractive index of 1.47 has been chosen for simulations [36]). To the best of our knowledge, this is the first paper that focuses on antifingerprint application in order to protect the color effect, resulting from the interference phenomena of semitransparent oxide layers manufactured by laser radiation. The aim of this paper is to shed light on the possibility of solving the problem of protecting thin oxide layers, which may exert a significant impact on various applications.

\section{Materials and Methods}

2.1. Substrates. The research was conducted on plates made of a commonly used type of titanium (grade 2, chemical composition: $\mathrm{Ti}=99.2 \%, \mathrm{Fe}=0.3 \%_{\max }, \mathrm{O}=0.25 \%_{\max }, \mathrm{C}=$ $0.08 \%_{\max }, \mathrm{N}=0.03 \%_{\max }$, and $\mathrm{H}=0.02 \%_{\max }$ ) with dimensions of $20 \times 20 \mathrm{~mm}$ and thicknesses of $1 \mathrm{~mm}$. Samples were irradiated over a $15 \times 15 \mathrm{~mm}$ surface (Figure 1(a)). The plates were precoated with an antiscratch, polymer foil, which was removed before the experiment (the plates had also been washed in an ultrasonic cleaner filled with isopropyl alcohol). The samples were marked in the atmospheric air.

2.2. Laser Marking Setup. Experiments were conducted using a Ytterbium $\mathrm{Yb}^{3+}$ : glass fiber laser $(\lambda=1062 \mathrm{~nm})$ with an average output power of $20 \mathrm{~W}$, beam quality factor $M^{2} \leq 1.2$, constant pulse duration of about $230 \mathrm{~ns}$, and pulse repetition rate PRR within the range of $20-80 \mathrm{kHz}$ (IPG, YLP series). The laser system (Trotec, ProMarker) was equipped with a galvanometer-based optical scanner allowing the beam to be deflected within an area of the irradiated substrate. The laser beam was focused on the target through a $160 \mathrm{~mm}$ focal length $F$-Theta lens. The beam diameter $2 \omega_{0}$ at the focal point was approximately $40 \mu \mathrm{m}$. In order to stabilize the initial temperature of the substrate at $20 \pm 0.1^{\circ} \mathrm{C}$, a thermoelectric cooler and a temperature controller were used. A block diagram of the system is shown in Figure 1(a) [6].

2.3. Laser Treatment. In order to conduct the research on real data, laser color-marked samples were prepared. By changing the laser energy density, various surface colors can be achieved. For the purpose of our experiment, six values of accumulated fluence $F_{A}$ were chosen between 171 and $370 \mathrm{~J} / \mathrm{cm}^{2}$ (Figure 2).

The accumulated laser fluence (in the central point of one line of the process) was defined as follows [4]:

$$
F_{A}=\frac{2 \sqrt{2} P}{\pi \omega_{0} V},
$$

where $P$ is the average laser power, $\omega_{0}$ is the radius of the laser beam at the focal point, and $V$ is the scanning speed of the sample.

The samples were irradiated with a hatching distance of $10 \mu \mathrm{m}$. For all the investigated cases, the same pulse repetition rate was used with $\mathrm{PRR}=80 \mathrm{kHz}$ as well as a constant value of optical power $P=6.9 \mathrm{~W}$. A summary of process parameters for individual samples is given in Table 1.

2.4. Colorimetric Analysis. For the measurement of reflection and colorimetric analysis, an optical fiber spectrometer was used, AvaSpec StartLine (Avantes). The measurement system consists of a power supply, integrating sphere with the insidebuild light source (halogen lamp) and a spectrophotometer. A block diagram of the system is shown in Figure 1(b). As 


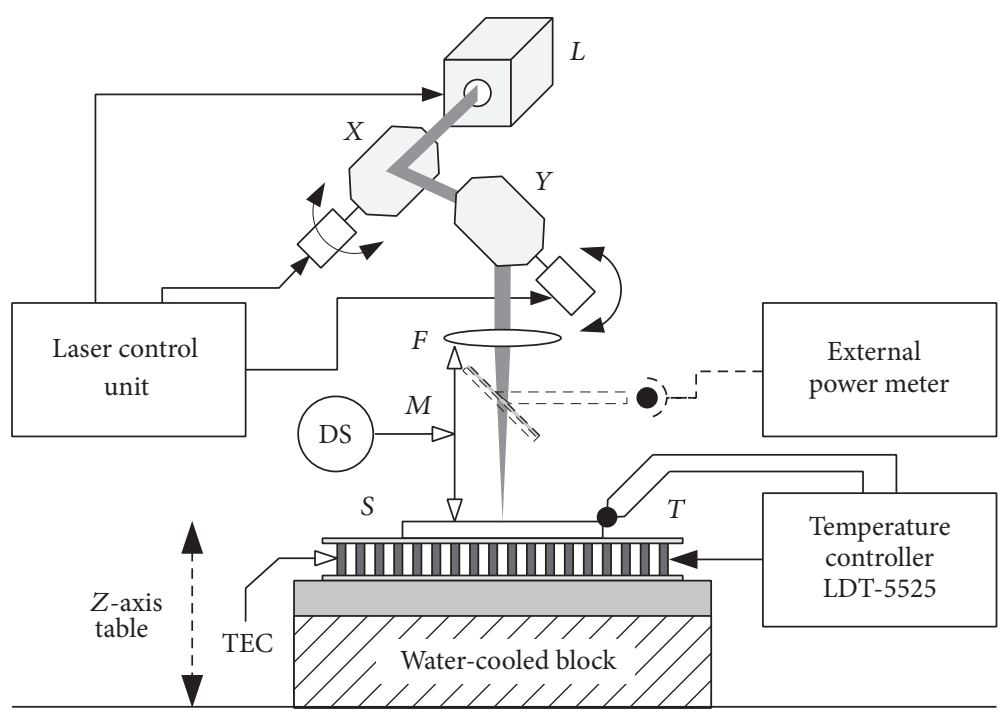

(a)

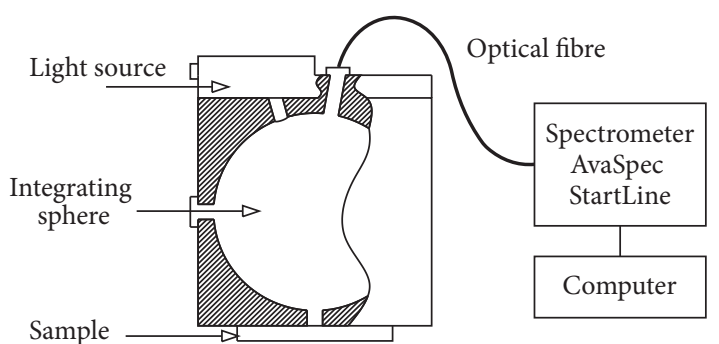

(b)

FIGURE 1: Block diagram of the system used for (a) sample preparation ( $L$ : laser; $F$ : F-Theta lens; DS: distance sensor; $T$ : temperature sensor; TEC: thermoelectric cooler; $S$ : tested sample; $X, Y, Z$ : axes of the system) [6] and (b) color measurements.
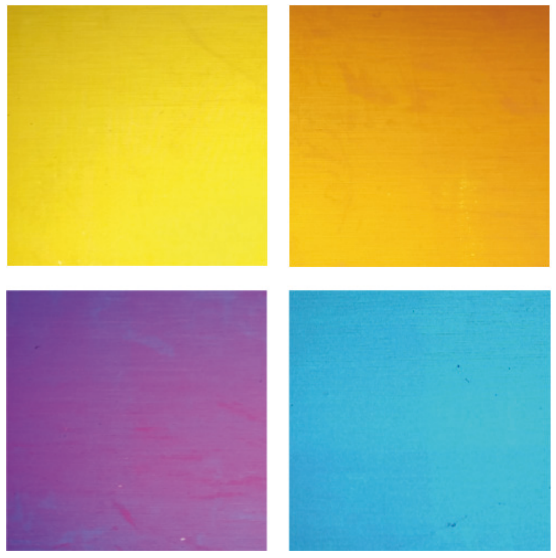

(a)
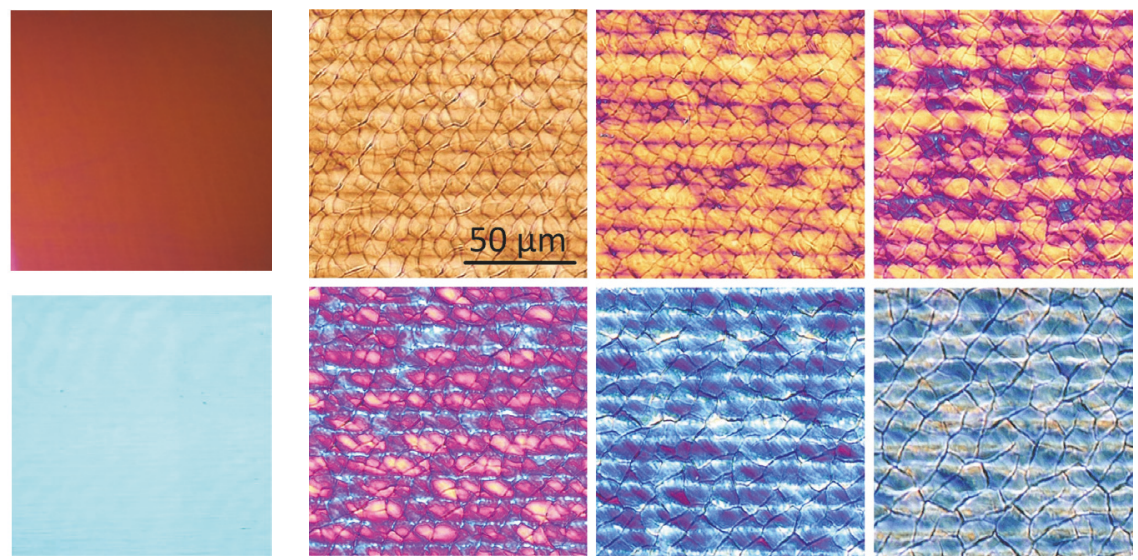

(b)

Figure 2: Photos of the six samples (thin oxide films creating color effects) manufactured using laser-induced heating in an air environment: (a) Canon EOS 50D camera and (b) Keyence VHX-5000 digital microscope.

reference material for reflectance and color measurements, a mirror plate (Avantes) was used. In this work, all the measurements were performed using AvaSoft software with the light source D55 (5504 K color temperature), standard observer (associated with the characteristics of the human eye), and color according to the CIE $L^{*} a^{*} b^{*}$ model [43]. Statistical research has shown that the color difference $\Delta E^{*}{ }_{\text {Lab }}<7$ is acceptable in decorative applications and printing [44] so this error has been selected as a boundary value for further considerations.

2.5. Theoretical Model. In order to determine the reflectance $R$ as a function of wavelength $\lambda$ and viewing angle $\theta$ and generate the resulting color, radiation analysis based on geometrical optics was necessary. To convert the information from the spectral form (e.g., transmission spectrum $T$ and reflectance $R$ in wavelength function $\lambda$ ) to any color space, at the beginning the data have to be converted to $X Y Z$ space and then transformed into $L^{*} a^{*} b^{*}$. The procedures with all the equations are well described in [45-47].

A three-layer (air, titanium oxide, and titanium) model of interference effects occurring in a thin layer of titanium oxide is shown in Figure 3 [47].

In order to create a theoretical model of interference effect, the energetic reflection coefficient has to be determined. For this purpose, the following should be considered: phase delay (the real part), wave attenuation (the imaginary component) after passing through a layer having a thickness $d$, polarization, reflection and transmission coefficient for the wave propagating in the direction of incidence $\bar{r}_{u}, \bar{t}_{u}$ (where $u$ is the index of layer), and reflection and transmission coefficient for the wave propagating in the direction opposite 
TABLE 1: Set of process parameters selected for the experiment and measured $L^{*} a^{*} b^{*}$ values.

\begin{tabular}{lcccccccc}
\hline Color & $\begin{array}{c}F_{A} \\
\left(\mathrm{~J} / \mathrm{cm}^{2}\right)\end{array}$ & $\begin{array}{c}V \\
(\mathrm{~mm} / \mathrm{s})\end{array}$ & $\begin{array}{c}P \\
(\mathrm{~W})\end{array}$ & $\begin{array}{c}\text { PRR } \\
(\mathrm{kHz})\end{array}$ & $\begin{array}{c}H \\
(\mu \mathrm{m})\end{array}$ & $L^{*}$ & $a^{*}$ \\
\hline Yellow & 171 & 182 & & & & 59.22 & 9.52 & 34.48 \\
Orange & 217 & 143 & & & & 44.56 & 21.72 \\
Red & 241 & 129 & 6.9 & 80 & 10 & 36.94 & 27.51 & 1.48 \\
Purple & 272 & 114 & & & & 31.64 & 24.16 & -24.12 \\
Blue & 330 & 94 & & & & 39.98 & -2.40 & -27.33 \\
Light blue & 370 & 84 & & & & 47.83 & -7.62 & -10.05 \\
\hline
\end{tabular}

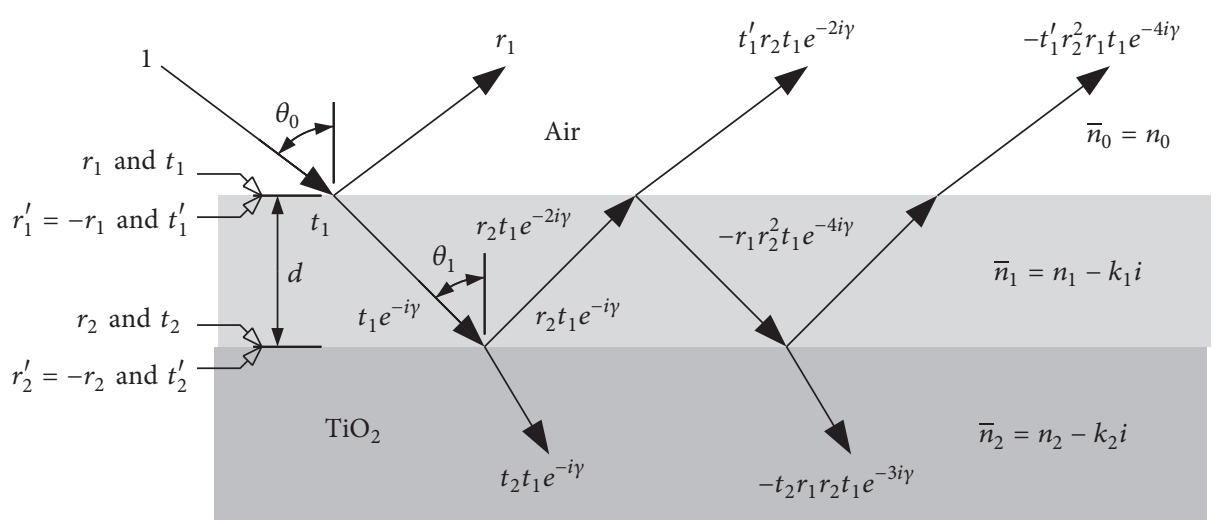

FIGURE 3: Reflection $\bar{r}_{u}^{\prime}$ and transmission $\bar{t}_{u}^{\prime}$ of light after passing through the thin layer of titanium oxide $\bar{n}_{1}$ on a substrate $\bar{n}_{2}$ [47].

to the direction of incidence $\bar{r}_{u}^{\prime}, \bar{t}_{u}^{\prime}$. The resultant amplitude of the reflected beams is the sum of the individual reflections $[47,48]$ :

$$
\bar{r}=\bar{r}_{1}+\bar{t}_{1}^{\prime} \bar{r}_{2} \bar{t}_{1} e^{-2 i \bar{\gamma}}-\bar{t}_{1}^{\prime} \bar{r}_{2}^{2} \bar{r}_{1} \bar{t}_{1} e^{-4 i \bar{\gamma}}+\cdots,
$$

where $\bar{\gamma}=(2 \pi / \lambda) \bar{n}_{1} d \cos \bar{\theta}_{1}$ determines both the phase delay (real part) and wave attenuation (imaginary component) relative to the incident beam after a single pass through a layer having a thickness $d\left(\bar{r}_{u}, \bar{t}_{u}\right.$ : reflection and transmission coefficient for the wave propagating in the direction of incidence and $\bar{r}_{u}^{\prime}, \bar{t}_{u}^{\prime}$ : reflection and transmission coefficient for the wave propagating in the opposite direction of incidence). Considering that $\bar{t}_{1} \bar{t}_{1}^{\prime}=1-\bar{r}_{1}^{2}$, converging geometric progression defined by (3) can be written as follows [47, 48]:

$$
\bar{r}=\frac{\bar{r}_{1}+\bar{r}_{2} e^{-2 i \bar{\gamma}}}{1+\bar{r}_{1} \bar{r}_{2} e^{-2 i \bar{\gamma}}} .
$$

The intensity of reflected beam $R$ with respect to the intensity of the incident beam is determined by an energy reflection coefficient [48]:

$$
R=|\bar{r}|^{2}=\overline{r r}^{*}=\frac{\bar{r}_{1} \bar{r}_{1}^{*}+\bar{r}_{2} \bar{r}_{2}^{*}+\bar{r}_{1} \bar{r}_{2}^{*} e^{2 i \bar{\gamma}^{*}}+\bar{r}_{1}^{*} \bar{r}_{2} e^{-2 i \bar{\gamma}}}{1+\bar{r}_{1} \bar{r}_{2} \bar{r}_{1}^{*} \bar{r}_{2}^{*}+\bar{r}_{1}^{*} \bar{r}_{2}^{*} e^{2 i \bar{\gamma}^{*}}+\bar{r}_{1} \bar{r}_{2} e^{-2 i \bar{\gamma}}}
$$

Moreover, the value of energy reflection coefficient affects the polarization of the incident wave. For parallel polarization TM, the light reflectance factor is determined by

$$
\bar{r}_{\|}=\frac{\bar{n}_{0} \cos \theta_{1}-\bar{n}_{1} \cos \theta_{0}}{\bar{n}_{0} \cos \theta_{1}+\bar{n}_{1} \cos \theta_{0}} \text {. }
$$

For perpendicular polarization TE, the light reflectance factor is determined by

$$
\bar{r}_{\perp}=\frac{\bar{n}_{0} \cos \theta_{0}-\bar{n}_{1} \cos \theta_{1}}{\bar{n}_{0} \cos \theta_{0}+\bar{n}_{1} \cos \theta_{1}} .
$$

The resultant value of the reflectance $R$ is defined as the arithmetic mean for both waves TE and TM:

$$
R=\frac{R_{\|}+R_{\perp}}{2}, \quad \text { where } R_{\|}=\left|\bar{r}_{\|}\right|^{2}, R_{\perp}=\left|\bar{r}_{\perp}\right|^{2} \text {. }
$$

For a four-layer model, the formula for the resultant amplitude of the reflected beams takes the form:

$$
\bar{r}=\frac{\bar{r}+\bar{r}_{2} e^{-2 i \bar{\gamma}_{1}}+\bar{r}_{3} e^{-2 i\left(\bar{\gamma}_{1}+\bar{\gamma}_{2}\right)}+\bar{r}_{1} \bar{r}_{2} \bar{r}_{3} e^{-2 i \bar{\gamma}_{2}}}{1+\bar{r}_{1} \bar{r}_{2} e^{-2 i \bar{\gamma}_{1}}+\bar{r}_{1} \bar{r}_{3} e^{-2 i\left(\bar{\gamma}_{1}+\bar{\gamma}_{2}\right)}+\bar{r}_{2} \bar{r}_{3} e^{-2 i \bar{\gamma}_{2}}},
$$

where

$$
\begin{aligned}
& \bar{r}_{1}=\frac{\bar{n}_{0} \cos \theta_{1}-\bar{n}_{1} \cos \theta_{0}}{\bar{n}_{0} \cos \theta_{1}+\bar{n}_{1} \cos \theta_{0}}, \\
& \bar{r}_{2}=\frac{\bar{n}_{1} \cos \theta_{2}-\bar{n}_{2} \cos \theta_{1}}{\bar{n}_{1} \cos \theta_{2}+\bar{n}_{2} \cos \theta_{1}}, \\
& \bar{r}_{3}=\frac{\bar{n}_{2} \cos \theta_{3}-\bar{n}_{3} \cos \theta_{2}}{\bar{n}_{2} \cos \theta_{3}+\bar{n}_{3} \cos \theta_{2}}, \\
& \bar{\gamma}_{1}=\frac{2 \pi}{\lambda} \bar{n}_{1} d_{1} \cos \bar{\theta}_{1}, \\
& \bar{\gamma}_{2}=\frac{2 \pi}{\lambda} \bar{n}_{2} d_{2} \cos \bar{\theta}_{2},
\end{aligned}
$$




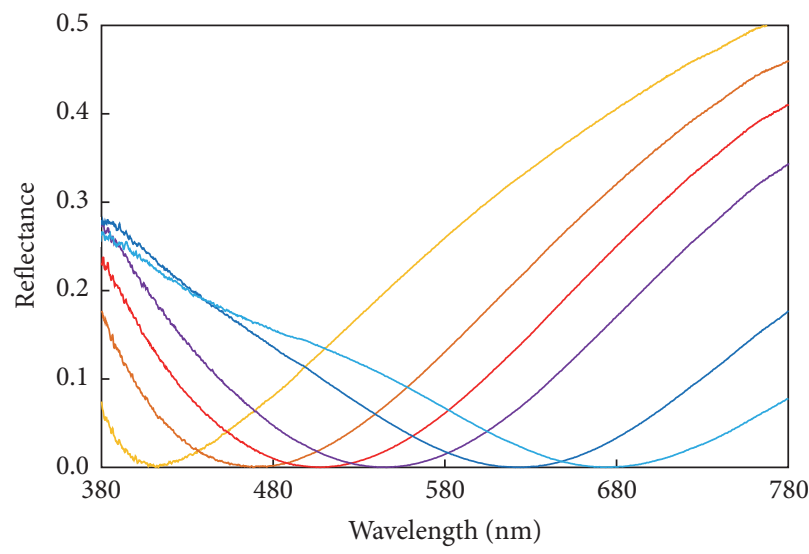

(a)

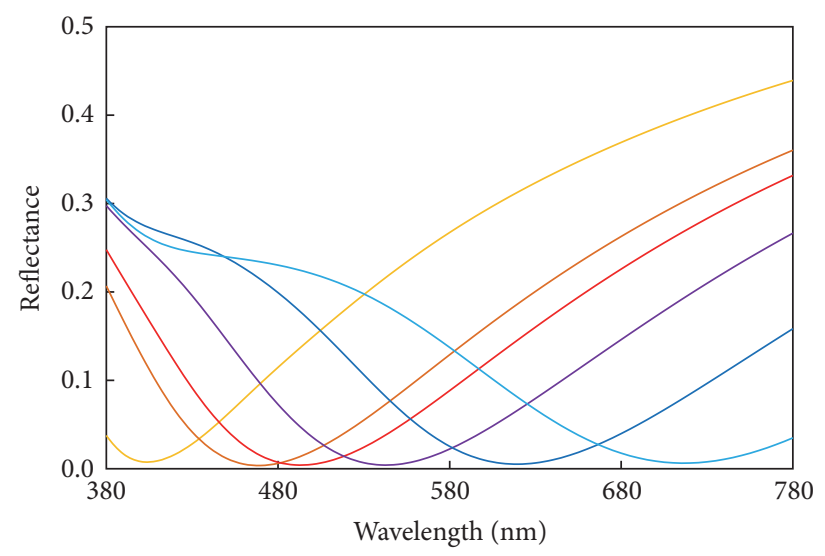

(b)

FIGURE 4: Reflectance as a function of wavelength: (a) measured using spectrophotometer and (b) modeled based on [7].

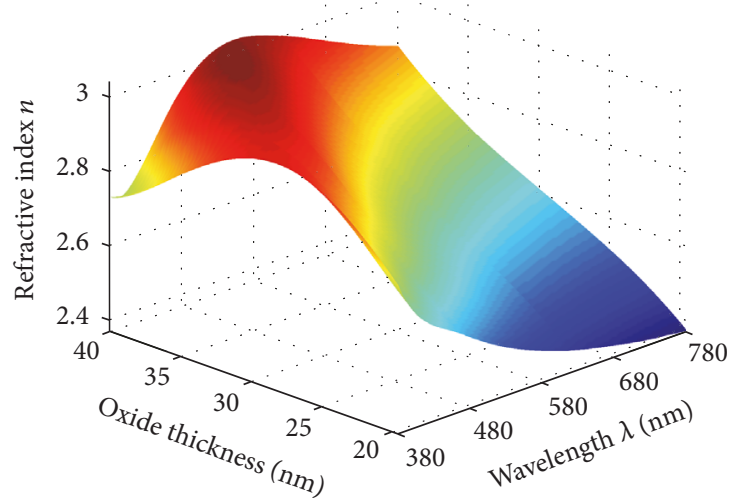

(a)

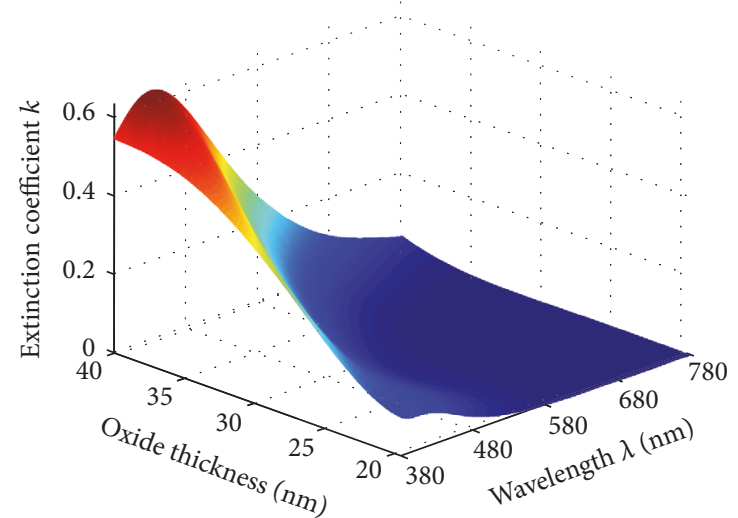

(b)

FIGURE 5: 2D interpolation of the dielectric constants of the laser manufactured oxide layers on titanium: (a) refractive index and (b) extinction coefficient.

where $\bar{n}_{0}=n_{0}$ (air), $\bar{n}_{1}=n_{1}-k_{1} i$ (protective layer), $\bar{n}_{2}=$ $n_{2}-k_{2} i$ (Ti oxide), and $\bar{n}_{3}=n_{3}-k_{3} i$ (Ti).

For the $U$-layer model, it is easier to use the matrix model [49] than to calculate all the reflections. Based on this model, the resulting sum of the amplitudes of the reflected beams $r$ from the various layers can be described as

$$
\begin{aligned}
M_{u} & =\left(\begin{array}{cc}
e^{-i \gamma_{u}} & 0 \\
0 & e^{-i \gamma_{u}}
\end{array}\right)\left(\begin{array}{cc}
1 & r_{u} \\
r_{u} & 1
\end{array}\right) \frac{1}{t_{u}}, \\
\widetilde{M} & =\frac{1}{t_{1}}\left(\begin{array}{cc}
1 & r_{1} \\
r_{1} & 1
\end{array}\right) M_{1} M_{2} \cdots M_{U-1}, \\
\left(\begin{array}{l}
1 \\
r
\end{array}\right) & =\left(\begin{array}{cc}
\widetilde{M}_{00} & \widetilde{M}_{01} \\
\widetilde{M}_{10} & \widetilde{M}_{11}
\end{array}\right)\left(\begin{array}{l}
t \\
0
\end{array}\right), \\
r & =\frac{\widetilde{M}_{10}}{\widetilde{M}_{00}} \\
t & =\frac{1}{\widetilde{M}_{00}} .
\end{aligned}
$$

The proposed thin layer model assumes that the layers have a thickness less than the coherence path of light reflected from the boundaries centers and that the path of coherence is significantly greater than the wavelength; also the refractive indices $n(\lambda)$ of the consequent layers have to be diminishing, in order to prevent reflection to the other side.

\section{Results and Discussion}

As described in Section 2.5 model utilizes thicknesses of the layers and their optical properties; all of these values were determined using ellipsometric spectroscopy of laser treated samples [7]. The measurements have confirmed that each color (Figure 2, Table 1) corresponds to defined thickness $d$ (Table 2). It should be noted that the process parameters used in this experiment allowed only for the production of oxides with thicknesses up to $40 \mathrm{~nm}$. The limitation was the ablation threshold of the substrate. Many authors [3, $5,8]$ present layers of other thicknesses produced under different process conditions (laser type, spot diameter) or were related to oxides from higher interference orders. It has also been noted that both the waveforms for refractive indices 


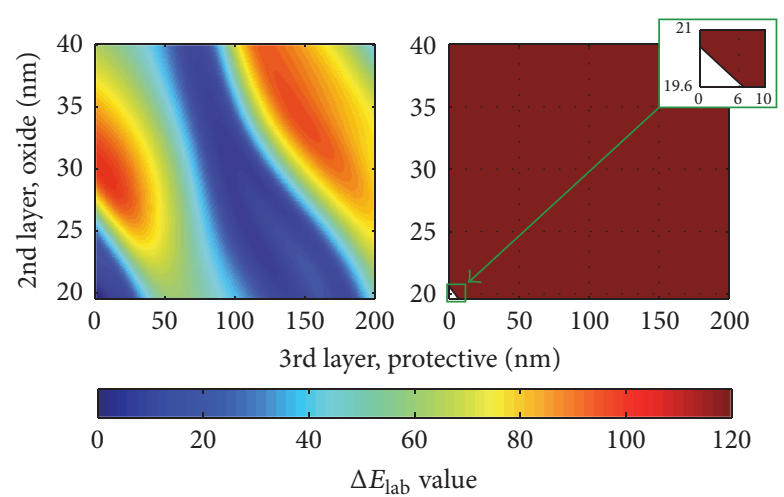

(a) $\Delta E_{\text {Lab }} d_{\text {oxide }}=19.6(\mathrm{~nm})$, yellow $\Delta E_{\text {Lab }}<7$

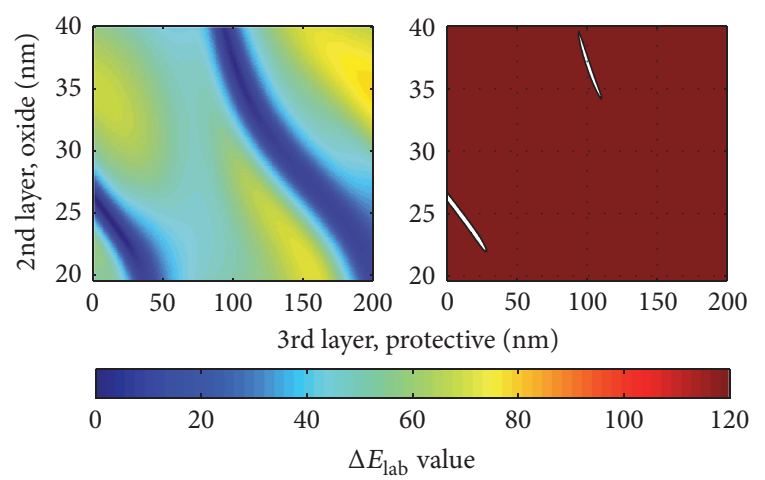

(c) $\Delta E_{\text {Lab }} d_{\text {oxide }}=26.4(\mathrm{~nm})$, red $\Delta E_{\mathrm{Lab}}<7$

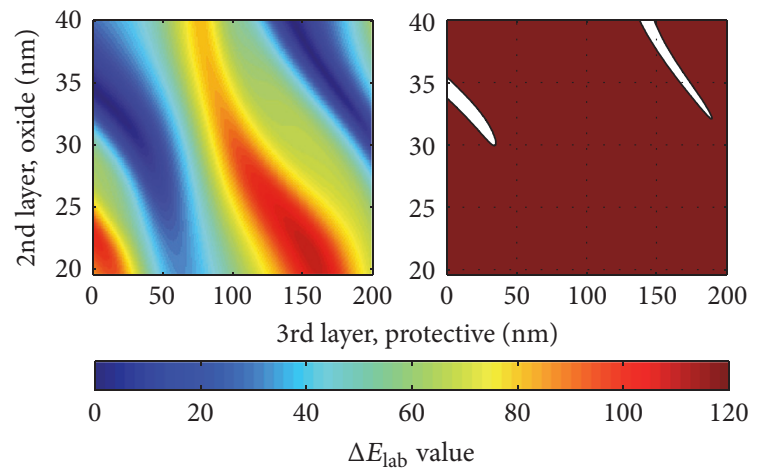

(e) $\Delta E_{\text {Lab }} d_{\text {oxide }}=34.5(\mathrm{~nm})$, blue $\Delta E_{\mathrm{Lab}}<7$

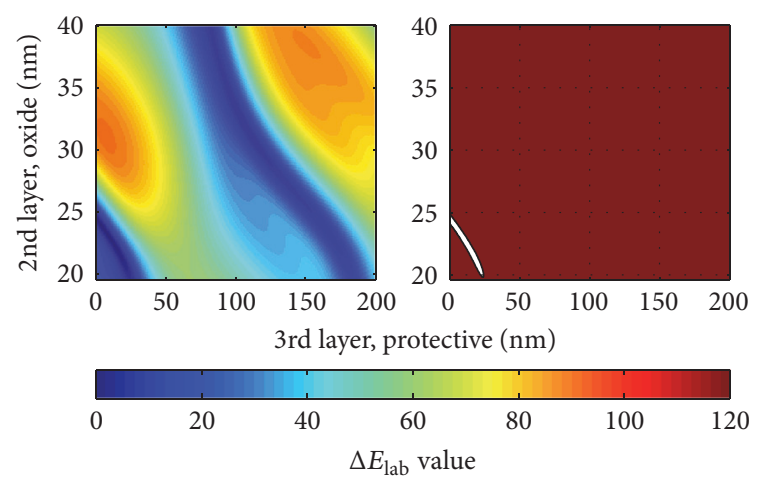

(b) $\Delta E_{\text {Lab }} d_{\text {oxide }}=24.5(\mathrm{~nm})$, orange $\Delta E_{\text {Lab }}<7$

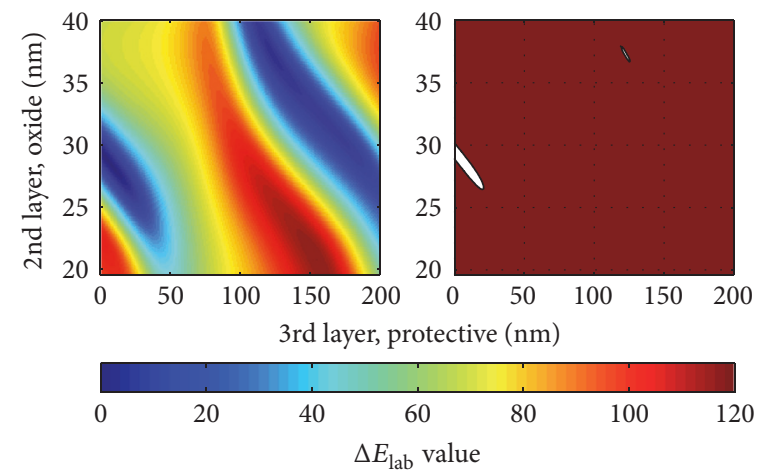

(d) $\Delta E_{\text {Lab }} d_{\text {oxide }}=29.5(\mathrm{~nm})$, purple $\Delta E_{\text {Lab }}<7$

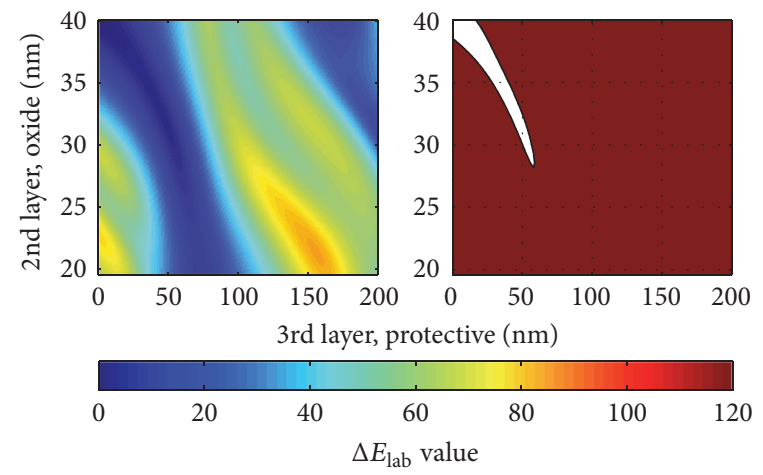

(f) $\Delta E_{\text {Lab }} d_{\text {oxide }}=40(\mathrm{~nm})$, I. blue $\Delta E_{\text {Lab }}<7$

Figure 6: The 2D spaces of the color difference $\Delta E^{*}{ }_{\text {Lab }}$ depending on the oxide thickness and the thickness of the protective layer with reference to six (a-e) examined colors. The white regions indicate the $\Delta E^{*}$ Lab value below 7 for the corresponding, mirrored color maps in each $(\mathrm{a}-\mathrm{e})$ case.

$n$ and extinction coefficients $k$ varied with the different colors (thicknesses of produced oxide due to changes in their chemical composition).

In order to verify the model by figures of merit, the characteristics of reflectance $R(\lambda)$ measured by spectrophotometer Avantes and modeled in Matlab ${ }^{\circledR}$ were compared (Figure 4). The results for all six analyzed colors were similar due to using real refractive indices $n(\lambda)$ and extinction coefficients $k(\lambda)$ (which were determined by ellipsometric measurements); thus the thicknesses of the created oxides were confirmed to be accurate.
The next step was then to move it forward to a 4-layer system. Such a model would consist of substrate (titanium) (1st), titanium oxide (2nd), protecting layer (3rd), and air (4th). In both theory and practice, after application of the additional layer on the already existing 3-layer system with the top layer of the substrate being titanium oxide, each of the examined colors will change. The aim for the proposed solution here is then to find if there exists a possibility of manipulating (change during the laser process) the thickness of the oxide layer in such a way that after applying the protective coating the resulting color will be the expected one. 


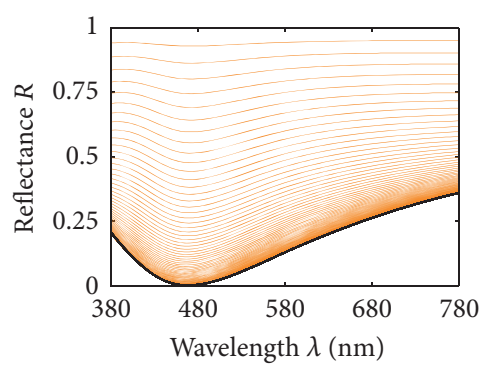

(a) $d_{\text {oxide }}=24.5(\mathrm{~nm}), d_{\text {prot }}=0(\mathrm{~nm})$, orange

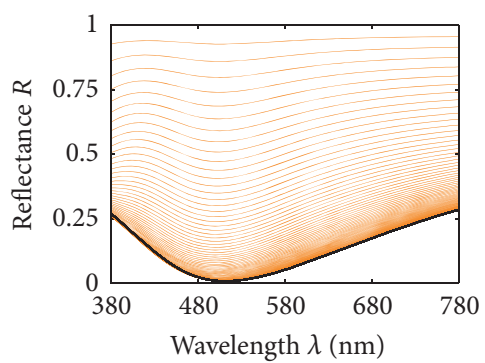

(d) $d_{\text {oxide }}=24.5(\mathrm{~nm}), d_{\text {prot }}=20(\mathrm{~nm})$, orange

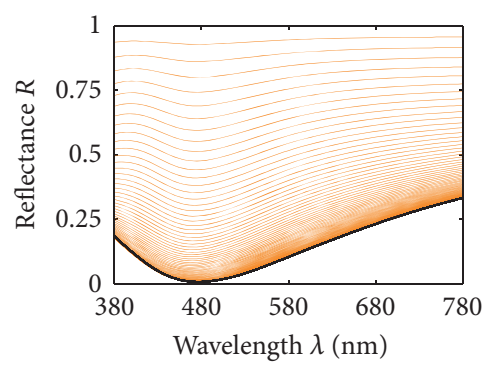

(g) $d_{\text {oxide }}=21(\mathrm{~nm}), d_{\text {prot }}=20(\mathrm{~nm})$, orange

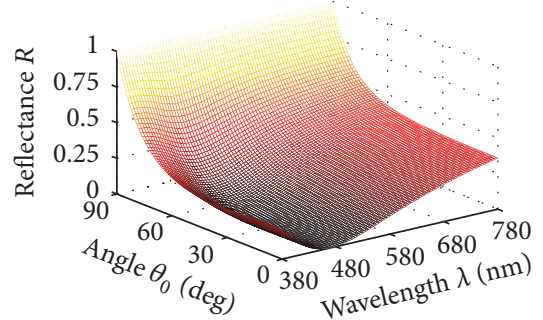

(b) $3 \mathrm{D}$ view, orange

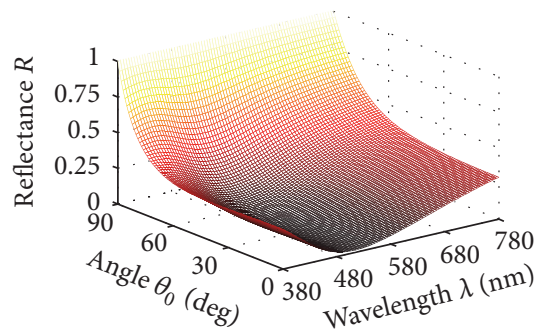

(e) 3D view, orange

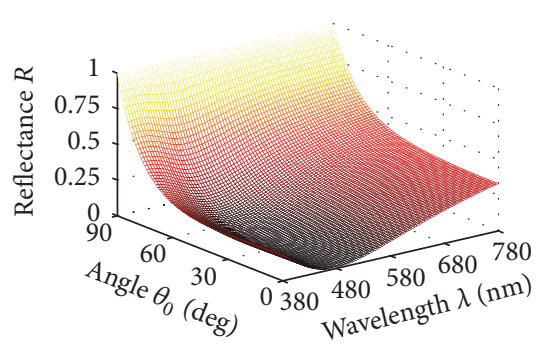

(h) 3D view, orange

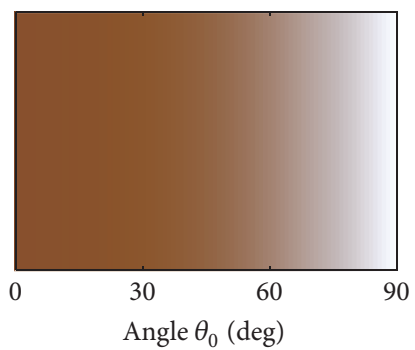

(c) RGB transform, orange

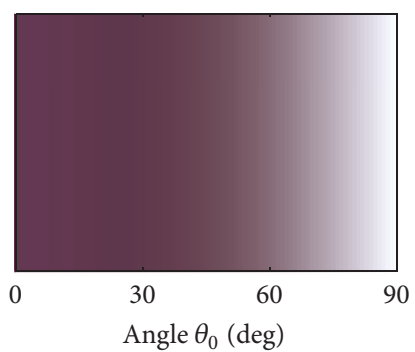

(f) RGB transform, orange

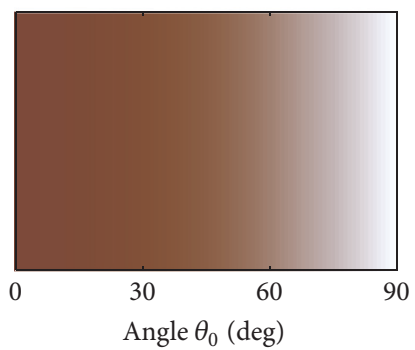

(i) RGB transform, orange

FIGURE 7: The results of four-layer system modeling in order to retain the original color (orange) after application of protective coating of a known refractive index: $(\mathrm{a}-\mathrm{c})$ reference sample without the $3 \mathrm{rd}$ layer, $(\mathrm{d}-\mathrm{f})$ effect of application of $20 \mathrm{~nm}$ of the $3 \mathrm{rd}$ layer, and ( $\mathrm{g}-\mathrm{i}$ ) the adaptation of the oxide thickness in order to reproduce the expected color after the application of the 3rd layer.

TABLE 2: The oxide thickness for each of the produced colors [7].

\begin{tabular}{lcccccc}
\hline Color & Yellow & Orange & Red & Purple & Blue & Light blue \\
\hline$d(\mathrm{~nm})$ & 19.6 & 24.5 & 26.4 & 29.5 & 34.5 & 40.0 \\
\hline
\end{tabular}

In order to perform such modeling and planning the values of $n$ and $k$ for all possible oxide thicknesses were necessary. These were achieved using numerical methods involving $2 \mathrm{D}$ interpolation of the already measured optical parameters for the existing substrates (Figure 5).

As the polynomials used for the interpolation were of a high order (with a demand of very low square error) we could predict only the values "within" the already measured range, that is, $19.6-40 \mathrm{~nm}$ oxide thickness (right outside the range, the $2 \mathrm{D}$ interpolated planes were rapidly changing their monotonicity).

From this point, the 4-layer system underwent a twoparameter evaluation where the first one was the 2 nd layer (oxide) thickness and the second was the 3rd layer (protective) thickness. The process took place six times with reference to six colors that needed to be preserved. As a result, $\operatorname{six} 2 \mathrm{D}$ spaces of $\Delta E_{\text {Lab }}^{*}$ errors were obtained (Figure 6). These figures present the difference between the original oxide color (ranging from yellow to light blue) and the combination of oxides of different thicknesses with protective layers of different thicknesses. The goals were to find if there exist regions in such $2 \mathrm{D}$ spaces where an oxide layer can be shifted to preserve a single color after application of a 3rd layer of " $x$ " $\mathrm{nm}$ thickness as well as to find if there exists a common region of $\Delta E^{*}$ Lab error below 7 (and preferably lower) for the whole color palette.

The results of the modeling show that each single color has two regions with the $\Delta E_{\text {Lab }}^{*}<7$ (some not visible due to cutting the figures only up to $200 \mathrm{~nm}$ thickness of the 3rd layer) (Figure 6). Nevertheless, for five colors (excluding yellow) there existed a common region between 0 (obviously none) and around $25 \mathrm{~nm}$ thickness of the protective layer. The excluded yellow color had also a part in the acceptable common region but only up to around $6 \mathrm{~nm}$ of protective layer. For each of the analyzed cases (apart from yellow), it can be seen (Figure 6) that after applying the additional protective 


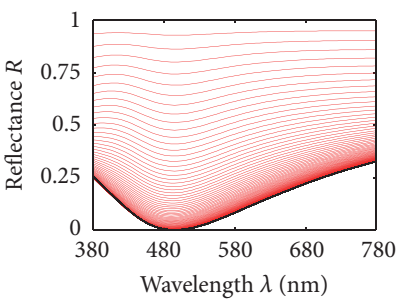

(a) $d_{\text {oxide }}=26.4(\mathrm{~nm}), d_{\text {prot }}=0(\mathrm{~nm})$, red

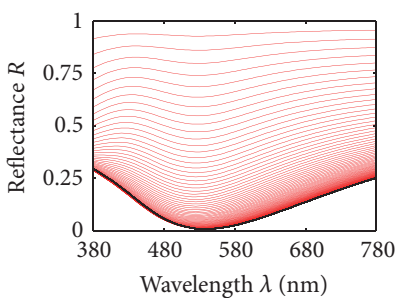

(d) $d_{\text {oxide }}=26.4(\mathrm{~nm}), d_{\text {prot }}=20(\mathrm{~nm})$, red

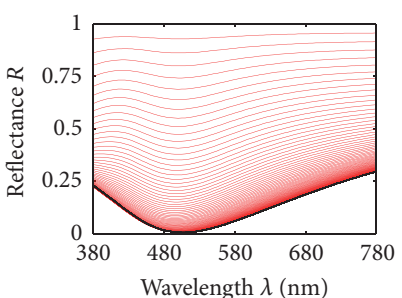

(g) $d_{\text {oxide }}=23.3(\mathrm{~nm}), d_{\text {prot }}=20(\mathrm{~nm})$, red

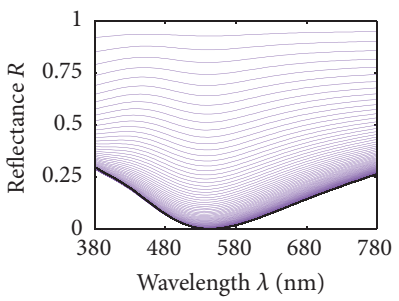

(a) $d_{\text {oxide }}=29.5(\mathrm{~nm}), d_{\text {prot }}=0(\mathrm{~nm})$, purple

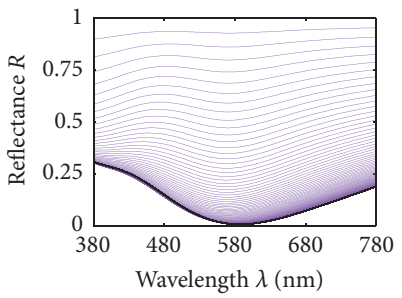

(d) $d_{\text {oxide }}=29.5(\mathrm{~nm}), d_{\text {prot }}=20(\mathrm{~nm})$, purple

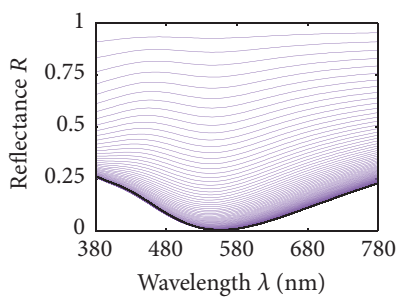

(g) $d_{\text {oxide }}=26.7(\mathrm{~nm}), d_{\text {prot }}=20(\mathrm{~nm})$, purple

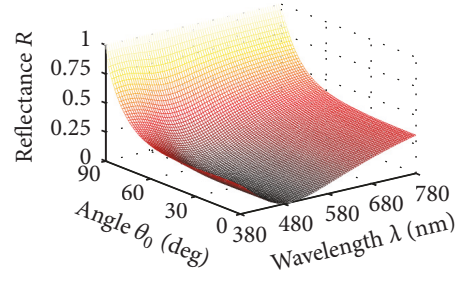

(b) $3 \mathrm{D}$ view, red

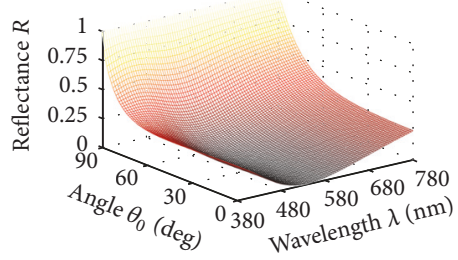

(e) $3 \mathrm{D}$ view, red

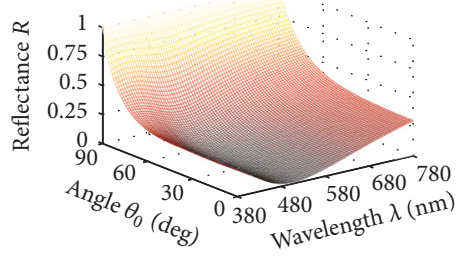

(h) 3D view, red

(A)

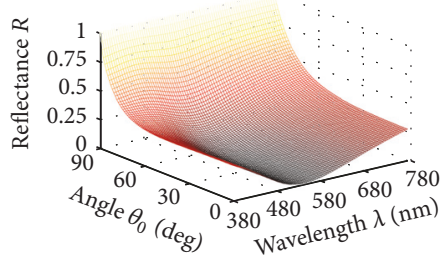

(b) 3D view, purple

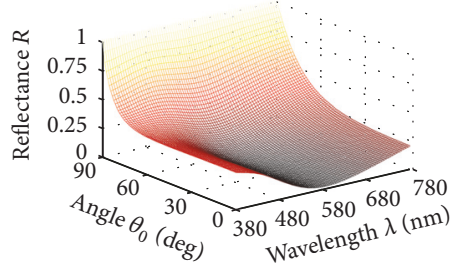

(e) 3D view, purple

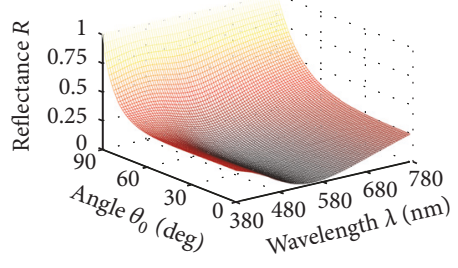

(h) $3 \mathrm{D}$ view, purple

(B)

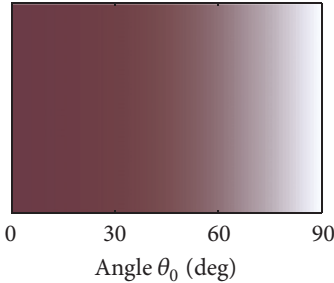

(c) RGB transform, red

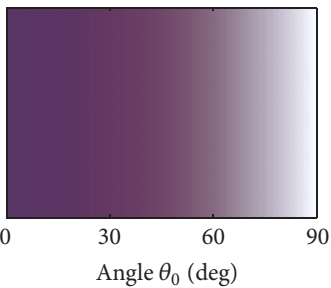

(f) RGB transform, red

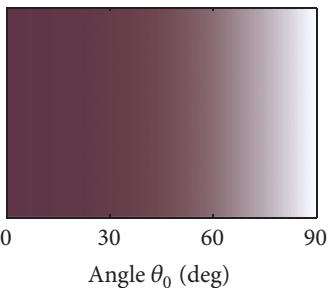

(i) RGB transform, red

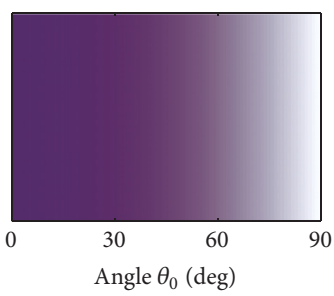

(c) RGB transform, purple

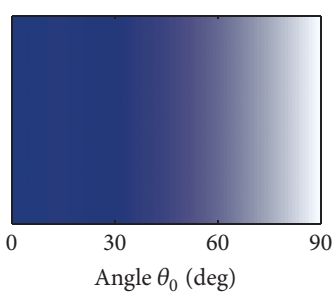

(f) RGB transform, purple

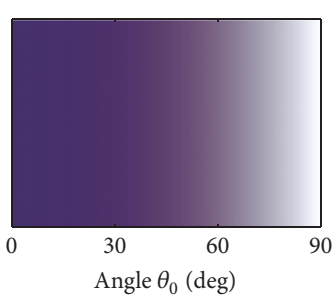

(i) RGB transform, purple

Figure 8: Continued. 


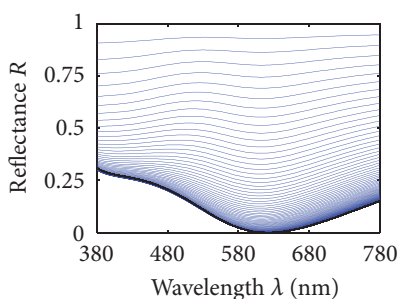

(a) $d_{\text {oxide }}=34.5(\mathrm{~nm}), d_{\text {prot }}=0(\mathrm{~nm})$, blue

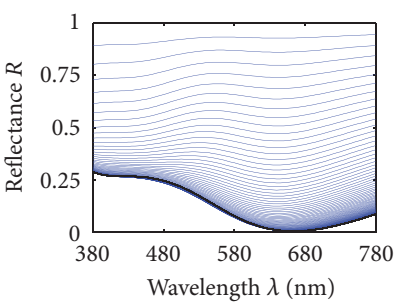

(d) $d_{\text {oxide }}=34.5(\mathrm{~nm}), d_{\text {prot }}=20(\mathrm{~nm})$, blue

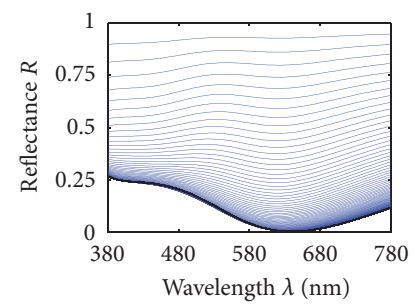

(g) $d_{\text {oxide }}=32.3(\mathrm{~nm}), d_{\text {prot }}=20(\mathrm{~nm})$, blue

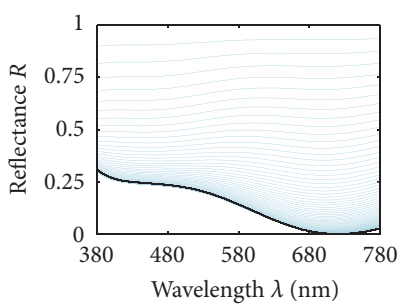

(a) $d_{\text {oxide }}=40(\mathrm{~nm}), d_{\text {prot }}=0(\mathrm{~nm})$, l. blue

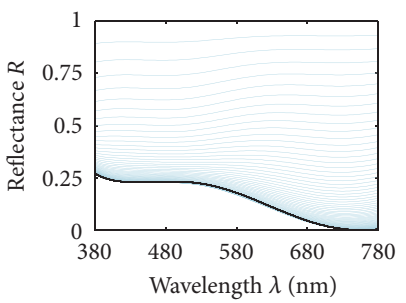

(d) $d_{\text {oxide }}=40(\mathrm{~nm}), d_{\text {prot }}=20(\mathrm{~nm})$, l. blue

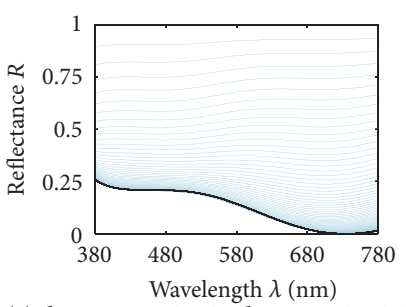

(g) $d_{\text {oxide }}=37.8(\mathrm{~nm}), d_{\text {prot }}=20(\mathrm{~nm})$, l. blue

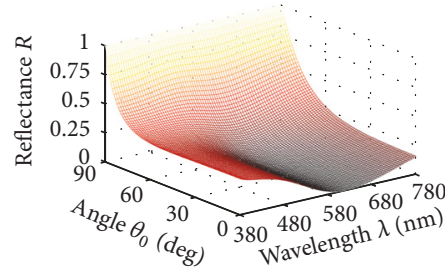

(b) $3 \mathrm{D}$ view, blue

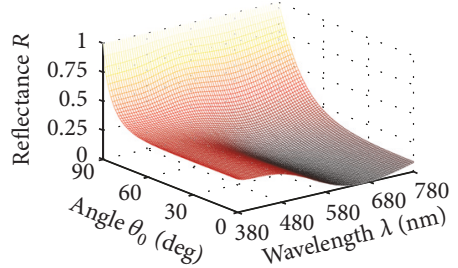

(e) $3 \mathrm{D}$ view, blue

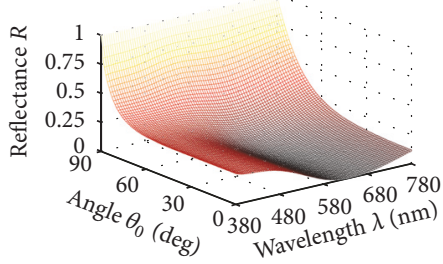

(h) 3D view, blue

(C)

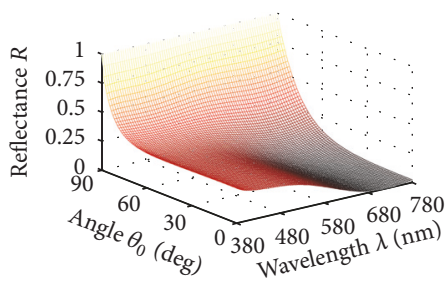

(b) $3 \mathrm{D}$ view, l. blue

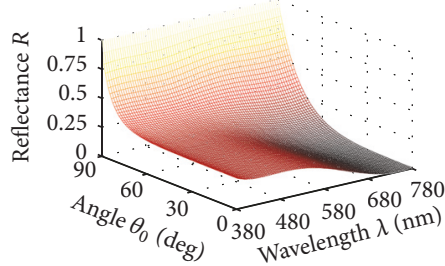

(e) $3 \mathrm{D}$ view, l. blue

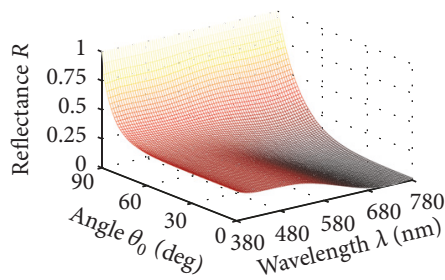

(h) $3 \mathrm{D}$ view, l. blue

(D)

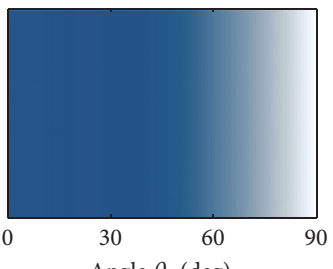

Angle $\theta_{0}$ (deg)

(c) RGB transform, blue

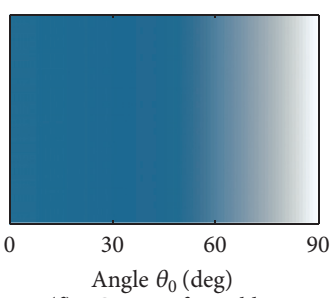

(f) RGB transform, blue

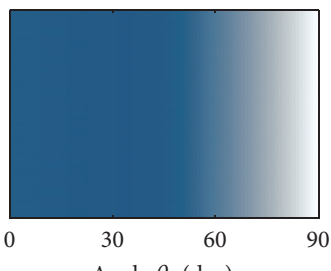

Angle $\theta_{0}$ (deg)

(i) RGB transform, blue

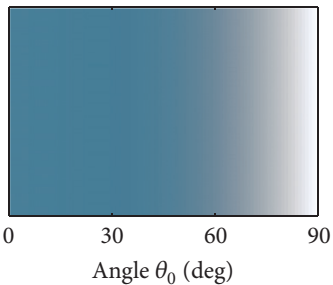

(c) RGB transform, l. blue

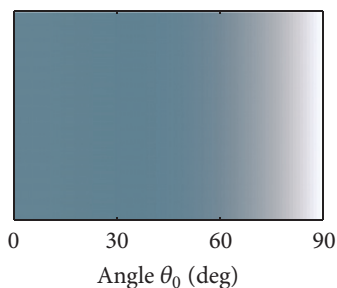

(f) RGB transform, l. blue

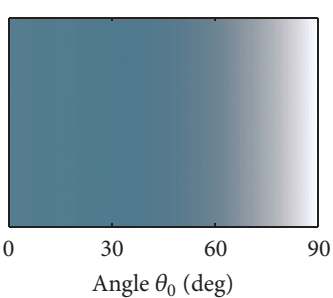

(i) RGB transform, l. blue

FIGURE 8: The results of a four-layer system modeling in order to retain the original color ((A) red, (B) purple, (C) blue, and (D) light blue) after application of protective coating of a known refractive index: $(a-c)$ reference sample without the 3rd layer, $(d-f)$ effect of application of $20 \mathrm{~nm}$ of the 3rd layer, and ( $\mathrm{g}-\mathrm{i}$ ) the adaptation of the oxide thickness in order to reproduce the expected color after the application of the 3rd layer. 
layer, the oxide thickness must decrease to maintain the color. Then following the shape of the other regions of acceptance (white areas on brown plots) it can be expected that yellow also has such a region but of a still unknown area.

Following the above, a $20 \mathrm{~nm}$ value of the protective (amphiphobic) layer was taken into further consideration. The oxide layers were reduced within the common region in a way to minimize $\Delta E_{\text {Lab }}^{*}$ for each of the colors (excluding yellow). The results for orange are presented in Figure 7 and the results for the other colors are presented in Figure 8 (the color tones of the presented RGB maps are a little inconsistent with the real obtained color which is due to graphics rendering in Matlab). The changes made into the original thicknesses, however, were not constant and varied for the orange-light blue palette between 2.2 and $3.1 \mathrm{~nm}$.

\section{Conclusions}

This paper presents the results of theoretical modeling of interference phenomena which occur in thin layer systems. The model took into account the number of layers, the oxide thickness, the actual dielectric constants of oxide layers (refractive index and extinction coefficient), optical properties of the medium, angle of observation, polarization and wavelength of the incidence light, and the assumed refractive index value of the protective, amphiphobic coating. The result of complex numerical calculations revealed that it is possible to retain the expected color (the interference effect) of the substrate after application of an additional 3 rd protective layer by foreseeing its impact on the already existing substrate-oxide-air system. It has been confirmed that for colors from orange to light blue there exist a common region of acceptable color difference $\left(\Delta E_{\text {Lab }}^{*}<7\right)$ so that a protective layer of constant thickness up to around $25 \mathrm{~nm}$ can be applied. To prove the expectations on the whole color palette, further measurements of optical properties for oxides below $19.6 \mathrm{~nm}$ have to be done.

The value of the amphiphobic layer's refractive index has been taken as a constant value for all the wavelengths but if the dielectric constants could be measured in the function of wavelength then they could also be applied into the evaluated parametrization of the presented model.

The amphiphobic coatings were chosen as they have the ability to repel contamination from the surface, so the additional, 5th thin layer system is less likely to happen and would not have to be taken into consideration; thus the perceived colors of the substrates will be preserved.

\section{Conflicts of Interest}

The authors declare that they have no conflicts of interest.

\section{References}

[1] L. Baufay, F. A. Houle, and R. J. Wilson, "Optical self-regulation during laser-induced oxidation of copper," Journal of Applied Physics, vol. 61, no. 9, pp. 4640-4651, 1987.

[2] S. O’Hana, A. J. Pinkerton, K. Shoba, A. W. Gale, and L. Li, "Laser surface colouring of titanium for contemporary jewellery," Surface Engineering, vol. 24, no. 2, pp. 147-153, 2008.
[3] A. P. del Pino, J. M. Fernández-Pradas, P. Serra, and J. L. Morenza, "Coloring of titanium through laser oxidation: comparative study with anodizing," Surface and Coatings Technology, vol. 187, no. 1, pp. 106-112, 2004.

[4] A. J. Antończak, B. Stępak, P. E. Kozioł, and K. M. Abramski, "The influence of process parameters on the laser-induced coloring of titanium," Applied Physics A: Materials Science and Processing, vol. 115, no. 3, pp. 1003-1013, 2014.

[5] S. Fujimoto, K. Tsujino, and T. Shibata, "Growth and properties of Cr-rich thick and porous oxide films on Type 304 stainless steel formed by square wave potential pulse polarisation," Electrochimica Acta, vol. 47, no. 4, pp. 543-551, 2001.

[6] A. J. Antończak, Ł. Skowroński, M. Trzcinski, V. V. Kinzhybalo, Ł. K. Łazarek, and K. M. Abramski, "Laser-induced oxidation of titanium substrate: analysis of the physicochemical structure of the surface and sub-surface layers," Applied Surface Science, vol. 325, no. C, pp. 217-226, 2015.

[7] Ł. Skowroński, A. J. Antończak, M. Trzcinski et al., "Optical properties of laser induced oxynitride films on titanium," Applied Surface Science, vol. 304, pp. 107-114, 2014.

[8] D. P. Adams, R. D. Murphy, D. J. Saiz et al., "Nanosecond pulsed laser irradiation of titanium: oxide growth and effects on underlying metal," Surface and Coatings Technology, vol. 248, pp. 38-45, 2014.

[9] E. Akman and E. Cerkezoglu, "Compositional and microscratch analyses of laser induced colored surface of titanium," Optics and Lasers in Engineering, vol. 84, pp. 37-43, 2016.

[10] D. N. Antonov, A. A. Burtsev, and O. Y. Butkovskii, "Coloration of a metal surface under pulsed laser irradiation," Technical Physics, vol. 59, no. 10, pp. 1503-1505, 2014.

[11] E. H. Amara, F. Haïd, and A. Noukaz, "Experimental investigations on fiber laser color marking of steels," Applied Surface Science, vol. 351, pp. 1-12, 2015.

[12] M. Kučera, M. Švantner, and E. Smazalová, "Influence of laser marking on stainless steel surface and corrosion resistance," in Proceedings of the 23rd International Conference on Metallurgy and Materials, METAL 2014, pp. 890-895, May 2014.

[13] S. K. Lawrence, D. P. Adams, D. F. Bahr, and N. R. Moody, "Environmental resistance of oxide tags fabricated on 304L stainless steel via nanosecond pulsed laser irradiation," Surface and Coatings Technology, vol. 285, pp. 87-97, 2016.

[14] J. S. Ruzankina and O. S. Vasiliev, "Study on possibility for the improvement of corrosion resistance of metals using laserformed oxide surface structure," Journal of Physics: Conference Series, vol. 735, no. 1, Article ID 012050, 2016.

[15] D. Prando, A. Brenna, F. M. Bolzoni, M. V. Diamanti, M. Pedeferri, and M. Ormellese, "Electrochemical anodizing treatment to enhance localized corrosion resistance of pure titanium," Journal of applied biomaterials functional materials, vol. 15, no. 1, 2017.

[16] V. Veiko, G. Odintsova, E. Gorbunova et al., "Development of complete color palette based on spectrophotometric measurements of steel oxidation results for enhancement of color laser marking technology," Materials and Design, vol. 89, pp. 684688, 2016.

[17] E. I. Ageev, Y. M. Andreeva, P. N. Brunkov et al., "Influence of light incident angle on reflectance spectra of metals processed by color laser marking technology," Optical and Quantum Electronics, vol. 49, no. 2, 2017. 
[18] T. Wu, C. Wei, M. Zhou, Y. Zhu, M. Song, and L. Wang, "Development of a mathematical model relating microstructures evolvement to optical appearance of laser-induced polychrome oxides on iron substrates," Journal of Laser Micro Nanoengineering, vol. 11, no. 3, pp. 366-371, 2016.

[19] M. V. Diamanti, B. Del Curto, and M. Pedeferri, "Interference colors of thin oxide layers on titanium," Color Research and Application, vol. 33, no. 3, pp. 221-228, 2008.

[20] B. Dusser, Z. Sagan, H. Soder et al., "Controlled nanostructrures formation by ultra fast laser pulses for color marking," Optics Express, vol. 18, no. 3, pp. 2913-2924, 2010.

[21] C. Velotti, A. Astarita, C. Leone, S. Genna, F. M. C. Minutolo, and A. Squillace, "Laser marking of titanium coating for aerospace applications," in Proceedings of the 48th CIRP International Conference on Manufacturing Systems, CIRP CMS 2015, pp. 975-980, June 2015.

[22] A. Patschger, A. Hopf, M. Güpner, and J. Bliedtner, "Laser material processing of medical titanium," Laser Technik Journal, vol. 13, no. 1, pp. 24-27, 2016.

[23] W. Navarrini, T. Brivio, D. Capobianco et al., "Anti-fingerprints fluorinated coating for anodized titanium avoiding color alteration," Journal of Coatings Technology Research, vol. 8, no. 2, pp. 153-160, 2011.

[24] M. Belhadjamor, M. El Mansori, S. Belghith, and S. Mezlini, "Anti-fingerprint properties of engineering surfaces: a review," Surface Engineering, pp. 1-32, 2016.

[25] A. M. Knowles, "Aspects of physicochemical methods for the detection of latent fingerprints," Journal of Physics E: Scientific Instruments, vol. 11, no. 8, article no. 001, pp. 713-721, 1978.

[26] Z. Tang, D. W. Hess, and V. Breedveld, "Fabrication of oleophobic paper with tunable hydrophilicity by treatment with nonfluorinated chemicals," Journal of Materials Chemistry A, vol. 3, no. 28, pp. 14651-14660, 2015.

[27] S. Cadd, M. Islam, P. Manson, and S. Bleay, "Fingerprint composition and aging: a literature review," Science and Justice, vol. 55, no. 4, pp. 219-238, 2015.

[28] C. Neinhuis and W. Barthlott, "Characterization and distribution of water-repellent, self-cleaning plant surfaces," Annals of Botany, vol. 79, no. 6, pp. 667-677, 1997.

[29] W. Barthlott and C. Neinhuis, "Purity of the sacred lotus, or escape from contamination in biological surfaces," Planta, vol. 202, no. 1, pp. 1-8, 1997.

[30] A. Otten and S. Herminghaus, "How plants keep dry: a physicist's point of view," Langmuir, vol. 20, no. 6, pp. 2405-2408, 2004.

[31] X. Gao and L. Jiang, "Water-repellent legs of water striders," Nature, vol. 432, no. 7013, p. 36, 2004.

[32] E. Bormashenko, Y. Bormashenko, T. Stein, G. Whyman, and E. Bormashenko, "Why do pigeon feathers repel water? Hydrophobicity of pennae, Cassie-Baxter wetting hypothesis and Cassie-Wenzel capillarity-induced wetting transition," Journal of Colloid and Interface Science, vol. 311, no. 1, pp. 212-216, 2007.

[33] L. Barbieri, E. Wagner, and P. Hoffmann, "Water wetting transition parameters of perfluorinated substrates with periodically distributed flat-top microscale obstacles," Langmuir, vol. 23, no. 4, pp. 1723-1734, 2007.

[34] W. Lee, M.-K. Jin, W.-C. Yoo, and J.-K. Lee, "Nanostructuring of a polymeric substrate with well-defined nanometer-scale topography and tailored surface wettability," Langmuir, vol. 20, no. 18, pp. 7665-7669, 2004.
[35] S. G. Lee, D. S. Ham, D. Y. Lee, H. Bong, and K. Cho, "Transparent superhydrophobic/translucent superamphiphobic coatings based on silica-fluoropolymer hybrid nanoparticles," Langmuir, vol. 29, no. 48, pp. 15051-15057, 2013.

[36] D. Babcock, Materials for Oleophobic and Hydrophobic Coatings, Sartomer, Boston, MA, USA, 2012, http://www.pcm411 .com/promoimages/2012_exhibitor_forum_presentations/2.5.pdf.

[37] W. C. Bigelow, D. L. Pickett, and W. A. Zisman, "Oleophobic monolayers. I. Films adsorbed from solution in non-polar liquids," Journal of Colloid Science, vol. 1, no. 6, pp. 513-538, 1946.

[38] X. Yao, Y. Song, and L. Jiang, "Applications of bio-inspired special wettable surfaces," Advanced Materials, vol. 23, no. 6, pp. 719-734, 2011.

[39] A. Nakajima, A. Fujishima, K. Hashimoto, and T. Watanabe, "Preparation of transparent superhydrophobic boehmite and silica films by sublimation of aluminum acetylacetonate," Advanced Materials, vol. 11, no. 16, pp. 1365-1368, 1999.

[40] L. Cao and D. Gao, "Transparent superhydrophobic and highly oleophobic coatings," Faraday Discussions, vol. 146, pp. 57-65, 2010.

[41] T. Matsubayashi, M. Tenjimbayashi, K. Manabe, K.-H. Kyung, B. Ding, and S. Shiratori, "A facile method of synthesizing sizecontrolled hollow cyanoacrylate nanoparticles for transparent superhydrophobic/oleophobic surfaces," RSC Advances, vol. 6, no. 19, pp. 15877-15883, 2016.

[42] D. Han and A. J. Steckl, "Superhydrophobic and oleophobic fibers by coaxial electrospinning," Langmuir, vol. 25, no. 16, pp. 9454-9462, 2009.

[43] K. McLAREN, "XIII-The Development of the CIE 1976 (L* $\left.\mathrm{a}^{*} \mathrm{~b}^{\star}\right)$ Uniform Colour Space and Colour-difference Formula," Journal of the Society of Dyers and Colourists, vol. 92, no. 9, pp. 338-341, 1976.

[44] F. Bunting, The Colorshop, Color Primer: An Introduction to the History of Color, Color Theory, and Color Measurement, 1998.

[45] CIE 15: Technical Report, Vienna, Vienna, 3rd edition, 2004, http://www.cdvplus.cz/file/3-publikace-cie15-2004/.

[46] ASTM Method E308, Standard Practice for Computing the Colors of Objects by Using the CIE System, American Society of Testing and Methods, 2001.

[47] A. Antonczak, Wybrane zagadnienia z laserowej modyfikacji material $\leq w$. Oficyna Wydawnicza Politechniki Wroclawskiej, 2014.

[48] E. Idczak, "Własności optyczne cienkich warstw medali, Romanowski, W. Cienkie warstwy metaliczne," in Własności optyczne cienkich warstw medali, pp. 107-154, PWN, WarszawaWroclaw, Cienkie warstwy metaliczne, 1974.

[49] S. Byrnes, "Multilayer optical calculations," 2016, https://arxiv .org/abs/1603.02720. 


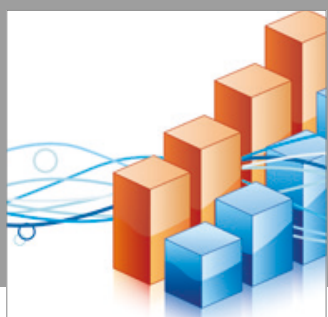

Advances in

Operations Research

vatersals

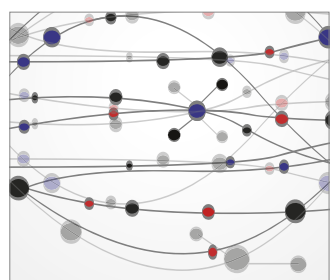

\section{The Scientific} World Journal
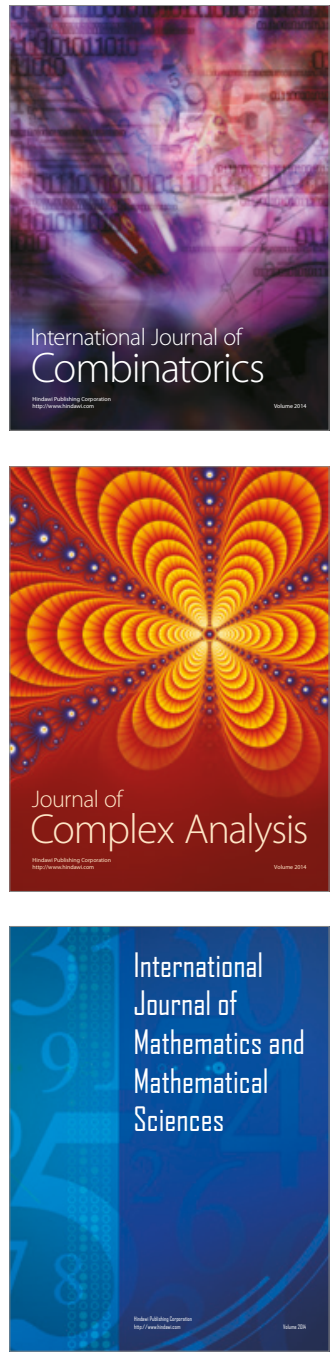
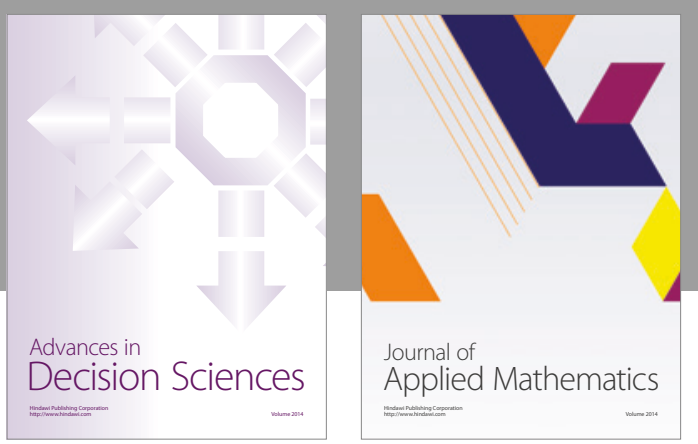

Algebra

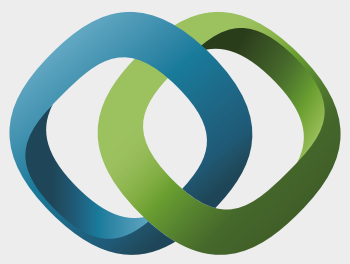

\section{Hindawi}

Submit your manuscripts at

https://www.hindawi.com
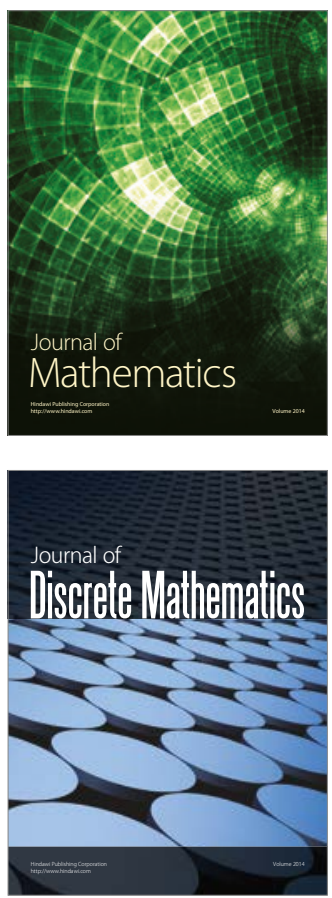

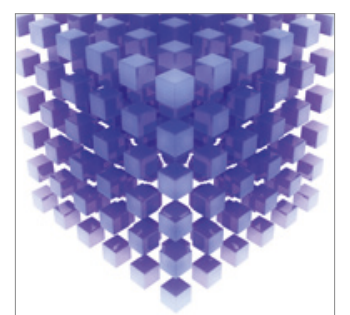

Mathematical Problems in Engineering
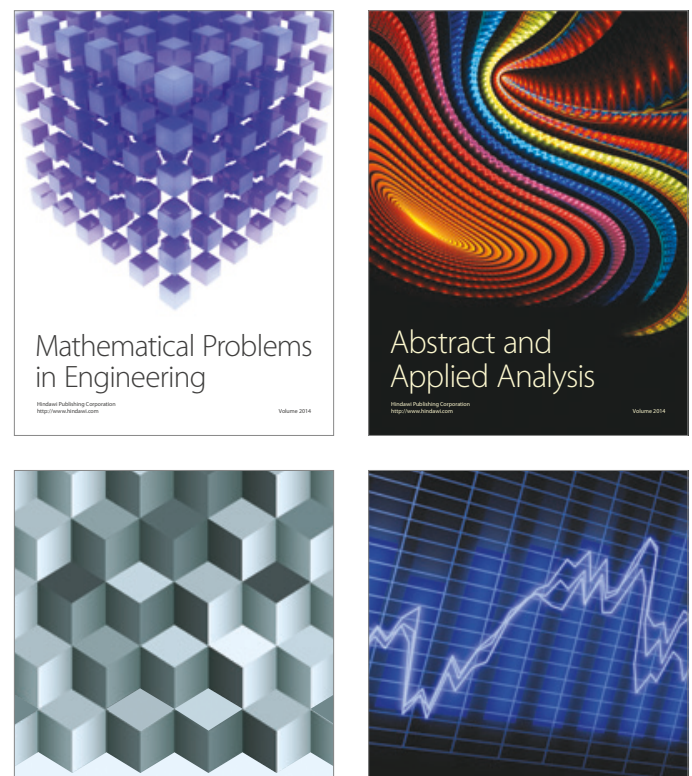

Journal of

Function Spaces

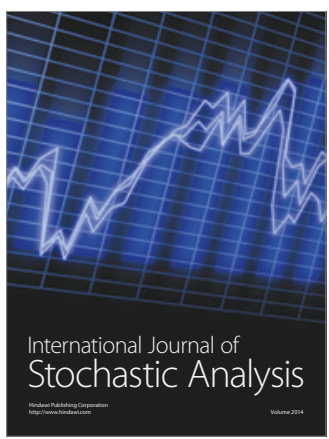

Probability and Statistics
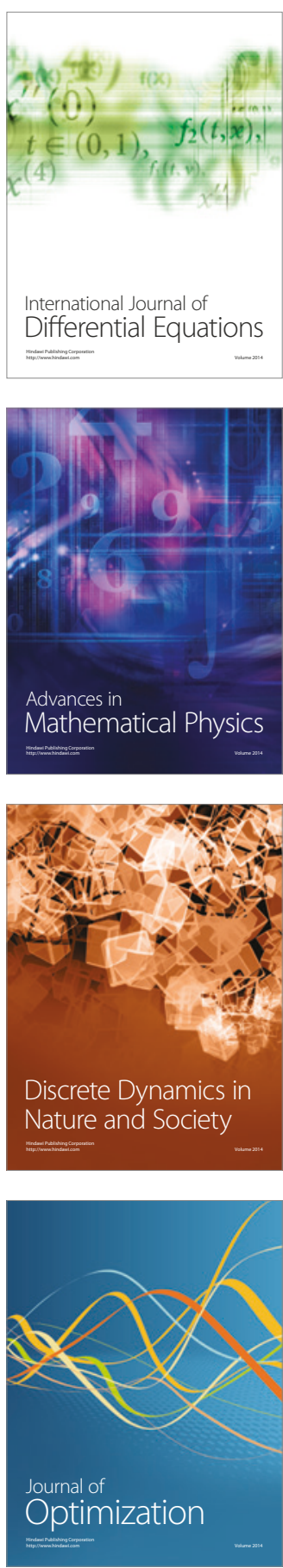